\title{
Measuring Efficiency and Productivity of Taxation: A Review of Tax System in Mozambique
}

\author{
Tuan Minh Le \\ The World Bank, 1818 H Street, NW, Washington, DC 20433, USA \\ Tel: 202-473-8485Ｅ-mail: tle@worldbank.org
}

Received: May 30, 2016 Accepted: June 8, 2016 Published: July 8, 2016

doi:10.5296/csbm.v3i2.9710 URL: http://dx.doi.org/10.5296/csbm.v3i2.9710

\begin{abstract}
The review of Mozambique's tax system highlights some key features. The country has established a solid legal framework for taxation. The overall tax intake is buoyant. The regime remains, however, in the process of transition. Tax burden on the corporate sector is relatively high compared with other SDAC countries. The complexity of tax regime, the mere existence of multiple schemes for small and medium taxpayers across tax codes, and the post 2009 overly generous system of fiscal incentives set in favor of certain types of investment, particularly capital-intensive, new mega projects-are among the few that collectively reflect the incoherence in the policy making spanning over the past decade. To set stage for policy recommendations for furthering the reforms of major taxes, this paper provides some estimates of productivity of CIT and VAT from regional perspectives. The analysis reconfirms the complexity and erosion of the base as a major channel for revenue leakage that more than compensating for the relatively high statutory rates in these taxes.
\end{abstract}

Keywords: Mozambique Tax System, Tax Productivity Measurement 


\section{Introduction}

Taxation in Mozambique has undergone major reforms since late 1990s. Tax regimes, however, remain in transition. Further tax reforms are being set at the critical juncture of economic and social developments: vibrant growth in the economy has been achieved but structural change in the economy is slow, and poverty still high. Since the end of the 1992 civil war, economic performance has been strong, with an average GDP growth of 7.4 percent during 1993-2012. According to the World Bank (2013), while poverty continued to decline during 2003 and 2009, it did so however at much slower rate: The national poverty headcount falling to 52 percent by 2009, a decline of just four percentage points, while income per capita grew by 36 percent over the same period, highlighting a growth elasticity of poverty reduction of only 0.1 . Agriculture remains a major sector in the economy. The most dynamic sector is the extractive industry, growing at a rate of more than 40 percent in 2012.

A snapshot of the key elements of fiscal architectures in selected SADC countries indicates Mozambique stands out with the following: (i) it remains a low income country; and (ii) while the country can keep the share of employment to the population of the age of 15 and above at more than 79 percent, certain aspects that may affect the taxable capacity include: Low working age population (51 percent), youth literature rate (just 72 percent), and high share of shadow economy (42 percent of GDP). (Note 1) Such factors exert direct impact on the revenue potential.

This study provides an assessment of tax policy in Mozambique in its transition. It is structured in complementarity with the other on-going studies and donor supports in the entire revenue reform agenda. It reviews the current tax regime setting of the major taxes, IRPC (corporate income tax, CIT), IRPS (personal income tax, PIT), and IVA (value added tax, VAT) that collectively account for around 70 percent of the total tax revenues or 17 percent of GDP in 2012. (Note 2) The analysis is conducted under the framework of a good tax system, targeting in particular the aspects of efficiency, equity, simplicity, revenue adequacy, and stability.

\section{Revenue Performance}

\subsection{Brief Review of Mozambique’s Tax System}

With major tax reforms undertaken since 1998, the Government of Mozambique (GOM) has strived to turn a relatively inefficient and archaic tax system into the one that broadly conforms to international practices. The GOM introduced the VAT in 1999, and the PIT and CIT in 2002. In 2006, Tax Authority (AT) was established with integration of tax and customs administrations. Also in 2006, a new General Law on Taxation was introduced with the aim to revise the entire revenue framework, including the duties and responsibilities of tax authorities, and the obligations and rights of taxpayers.

Though major progress has been achieved by 2006, prominent tax issues remained. These include excessive complexity, narrow base, low tax productivity, significant delays in VAT refund, high burden on companies, lack of public information and taxpayer services, and notably arbitrary and punitive enforcement (discussed in more detail later). 


\subsection{Trend Analysis: Revenue Collection and Persistent Revenue-Expenditures Gaps}

With substantial reforms, both in tax policy and tax administration, revenue collections surged during the 2000s. Total revenues in GDP rose steadily from 13 percent in 2004 to almost 21 percent in 2011, while tax revenues increased from 12 percent to more than 18 percent. The greatest rate of increase in total revenue and tax collection was attained by 11.4 percent in 2009-2010 and by almost 10 percent in 2008-2009 respectively. Until 2015, revenue collection, however, persistently fell behind public expenditures, indicating that the country cannot easily grow out of aid dependence any time soon. Adding to this overall expenditure-revenue collection gap is the recent estimates by the IMF (2013): strong revenue intakes from new mega projects in extractive industries may not be forthcoming until beyond the next 4-5 years.

The major contributors to fiscal resources are VAT, IRPC, and IRPS, which, in 2012, account for 32.6, 25.2, and 12.2 of the total collection respectively. At the current stage, taxes on goods and services represent around 50 percent of total tax revenues, while taxes on income profits account for about 38 percent and taxes on international trade for 10 percent. (Note 3)

\subsection{Tax Buoyancy}

Table 1 shows the estimates of buoyancy of overall tax collection for the period 2005-2015 (projected). The results indicate the country's tax has constantly been buoyant during 2005-2013, whereas the buoyancy is projected to be sharply reversed in 2014 .

Table 1. Tax buoyancy estimates (2005-2015)

\begin{tabular}{|l|l|l|l|l|l|l|l|l|l|l|l|l|}
\hline & $\mathbf{2 0 0 4}$ & $\mathbf{2 0 0 5}$ & $\mathbf{2 0 0 6}$ & $\mathbf{2 0 0 7}$ & $\mathbf{2 0 0 8}$ & $\mathbf{2 0 0 9}$ & $\mathbf{2 0 1 0}$ & $\mathbf{2 0 1 1}$ & $\mathbf{2 0 1 2}$ & $\mathbf{2 0 1 3}$ & $\mathbf{2 0 1 4}$ & $\mathbf{2 0 1 5}$ (Proj.) \\
\hline $\begin{array}{l}\text { Growth rate, } \\
\text { taxes, real }\end{array}$ & & & & & & & & & & & & \\
\hline $\begin{array}{l}\text { Growth rate of } \\
\text { GDP, real }\end{array}$ & & 0.144 & 0.152 & 0.111 & 0.090 & 0.172 & 0.131 & 0.166 & 0.225 & 0.202 & -0.041 & 0.112 \\
\hline Buoyancy & & 2.351 & 1.536 & 2.221 & 1.069 & 2.983 & 8.695 & 1.896 & 2.329 & 3.471 & -0.483 & 1.282 \\
\hline $\begin{array}{l}\text { Memorandum } \\
\text { item: }\end{array}$ & & & & & & & & & & & & \\
\hline $\begin{array}{l}\text { CPI end of period } \\
(2004=100)\end{array}$ & 1 & 1.111 & 1.216 & 1.340 & 1.423 & 1.483 & 1.730 & 1.824 & 1.864 & 1.978 & 2.087 & 2.204 \\
\hline
\end{tabular}

Source: Government of Mozambique and authors’ estimates

\subsection{Tax Burden On Corporate Sector: A Comparative Analysis}

Total tax rate as a share of commercial profits in SADC countries is summarized in Table 2. (Note 4) The data show that Mozambique imposes relatively high tax burden on corporate sector. The rate remains constant during 2005-12 at 37.5 percent of total commercial profits. In 2005, it ranked fifth highest among the 12 countries in the SADC sample. In 2013, the rate put 
the Mozambique in the third highest tax burden. During the period, Madagascar and South Africa moved in opposite direction: their ranking went down from the second and fourth highest to the fifth and eighth, respectively.

Table 2. Total tax rate in commercial profits in selected SADC countries

\begin{tabular}{|l|l|l|l|l|l|l|l|l|l|}
\hline Country & $\mathbf{2 0 0 5}$ & $\mathbf{2 0 0 6}$ & $\mathbf{2 0 0 7}$ & $\mathbf{2 0 0 8}$ & $\mathbf{2 0 0 9}$ & $\mathbf{2 0 1 0}$ & $\mathbf{2 0 1 1}$ & $\mathbf{2 0 1 2}$ & $\mathbf{2 0 1 3}$ \\
\hline Angola & 52.1 & 52.1 & 52.1 & 52.1 & 52.1 & 52.1 & 52.1 & 52.1 & 52.1 \\
\hline Botswana & 17.1 & 17.1 & 17.1 & 17.1 & 17 & 19.5 & 19.5 & 25.4 & 25.4 \\
\hline Madagascar & 46.9 & 46.5 & 46.5 & 42.6 & 38.4 & 37.7 & 37.1 & 36.4 & 35.8 \\
\hline Mozambique & 37.5 & 37.5 & 37.5 & 37.5 & 37.5 & 37.5 & 37.5 & 37.5 & 37.5 \\
\hline Mauritius & 26.2 & 26 & 24.2 & 25.8 & 26 & 27.2 & 27.7 & 27.5 & 28.2 \\
\hline Malawi & 33.4 & 33.4 & 33 & 32.2 & 26.3 & 25.9 & 29 & 32.4 & 34.9 \\
\hline Namibia & 25.8 & 25.8 & 25.8 & 22.8 & 22.3 & 22.3 & 21.8 & 21.8 & 21.8 \\
\hline Swaziland & 36.3 & 36.3 & 36.3 & 36.3 & 36.3 & 36.5 & 36.5 & 36.5 & 36.5 \\
\hline Tanzania & 43.8 & 43.8 & 43.9 & 44.4 & 44.4 & 44.4 & 44.9 & 44.9 & 44.9 \\
\hline South Africa & 37.6 & 37.1 & 36.5 & 33.7 & 29.8 & 30 & 32.4 & 32.7 & 30.1 \\
\hline Zambia & 15.4 & 15.4 & 15 & 15 & 15 & 14.3 & 14.4 & 15.1 & 15.1 \\
\hline Zimbabwe & 32.3 & 32.3 & 51.4 & 68.4 & 38.2 & 39.1 & 34.3 & 34.5 & 35.3 \\
\hline
\end{tabular}

Source: WDI

Table 3 allows us to break down further the composite indicator of tax rate in commercial profits into various components-profits tax, labor tax and contributions, and others. For Mozambique, in 2012/13, of the 37.5 percent of commercial profits, profits tax stands at almost 31 percent, the highest among the SADC countries in the sample. Although the increase in tax revenues over time is welcomed by the government, the private sector worries that high tax rates pose many constraints, as imbalance between tax collection and the expansion of business activity could occur (AFRODAD 2011).

Table 3. Taxes paid by businesses in SADC countries

\begin{tabular}{|l|l|l|l|l|}
\hline Country & Profit tax (\%) & Labor tax and contributions (\%) & Other taxes (\%) & Total tax rate (\% profit) \\
\hline Sub-Saharan Africa & 18.4 & 13.7 & 21.3 & 53.3 \\
\hline Angola & 25.2 & 9 & 17.9 & 52.1 \\
\hline Botswana & 21.7 & 0 & 3.6 & 25.4 \\
\hline Lesotho & 13.1 & 0 & 2.9 & 16 \\
\hline
\end{tabular}




\begin{tabular}{|l|l|l|l|l|}
\hline Madagascar & 14 & 20.3 & 1.5 & 35.8 \\
\hline Malawi & 20.7 & 9.6 & 4.6 & 34.9 \\
\hline Mauritius & 10.6 & 10.3 & 7.3 & 28.2 \\
\hline Mozambique & 30.9 & 4.5 & 2.1 & 37.5 \\
\hline Namibia & 17.7 & 1 & 3.1 & 21.8 \\
\hline Seychelles & 23.3 & 1.7 & 0.7 & 25.7 \\
\hline South Africa & 21.9 & 4.1 & 4.2 & 30.1 \\
\hline Swaziland & 28.2 & 4 & 4.3 & 36.5 \\
\hline Tanzania & 20.4 & 18 & 6.4 & 44.9 \\
\hline Zambia & 1.2 & 10.4 & 3.6 & 15.1 \\
\hline Zimbabwe & 20.8 & 5.1 & 9.4 & 35.3 \\
\hline
\end{tabular}

Source: IFC, Doing Business -Measuring Business Regulations, 2013

\section{Key Features of The CIT, PIT, VAT and Fiscal Incentives}

\subsection{CIT}

Corporate Income Tax Code (IRPC) has been enacted and amended by Decree 61/03.

Base: The CIT base is comprehensive as it includes income from capital gains, interest income (subject to a separate withholding tax of 20 percent). Most corporate entities - those with headquarters or permanent establishment (PE) in Mozambique-are subject to CIT based on their worldwide income. Other corporate entities (i.e. non-resident entities) are taxed on residence basis. The calculation of CIT taxable income follows international standards: taxable income equals to revenues minus costs of goods sold, fiscal depreciation, interest payments, transport/advertisement costs related to distribution and sales, research/consultancy and other costs of administrative nature (e.g., remuneration, expense allowances, pensions, and retirement supplements).

Depreciation. Fiscal depreciation is allowed according to straight line. Depreciation scheme consists of both tangible and non-tangible assets with the main depreciation rates basically in line with the ones applied in other countries in the region. However the depreciation structure is complicated, with a total of 20 categories. (Note 5)

Loss carried forward. Losses are allowed to be carried forward for up to five years.

Capital gains treatment. Capital gains and capital losses consist of the difference between the realization values net of costs/acquisition value, after deduction of amounts for depreciation. Historical purchase price is accounted for and is not adjusted for inflation for the calculation of capital gains taxable income.

Transfer pricing and thin capitalization. These provisions are provided in Articles 58-62 of the CIT Code. The inclusion of such provisions in the law follows an international modern CIT code. Transfer pricing becomes increasingly critical for Mozambique as the country is embracing more FDI and mega projects in extractive industries. The on-going IMF technical assistance is important for the country to build sufficient institutional framework and capacity in dealing with the complex, multi-faceted issues of transfer pricing. It is worth noting, however, the legal provision on thin capitalization remains unclear and subject to 
discretionary interpretation. (Note 6)

Fiscal incentives. Fiscal incentives are numerous and mixed in both CIT Code and the separate 2009 Fiscal Benefit Code. Exemptions from taxable income under the CIT code are allowed for by type of organization/ownership (state, municipalities, social security institutions, cooperatives, and public utilities), type of activities (cultural, recreational, and sporting activities). Further provisions for benefits provided under the Fiscal Benefits Code are analyzed in a separate section.

Rate. The CIT standard rate is 32 percent. However the rate structure is overly complex with multi-rates available. Particularly, agriculture and livestock activity as well as income from non-resident entities, telecommunications, transport, and equipment installation are subject to reduced rate of 10 percent, while charges that are not properly documented or expenses considered as confidential taxed at 35 percent. A rate of $20 \%$ is applicable to income subject to retention from the source and income from non-resident entities (in the form of withholding tax).

Simplified regime for CIT. Simplified system for determining business taxable profits is allowed in Article 54 of the CIT Code. Those entities that are not able to keep organized accounting records and earn a total annual turnover not exceeding MT 1,500,000,000 are eligible for this regime. Different coefficients are used for different types of incomes: taxable profit is ascertained by applying a coefficient of 0.20 to the value of sales of merchandise and products and a coefficient of 0.30 to other income.

\subsection{PIT}

A new Personal Income Tax Code (IRPS) has come into effect since January 1, 2003 and further changes to the law were made in 2008. In addition to PIT, other individual taxes include social security tax and local income taxes (varied by municipality).

Base: Residents are taxed on their worldwide income while non-residents are taxed on income arising from within Mozambique. The coverage is broad-including various types of income and remunerations. Income is classified into five categories: First Category: income from employment; Second: business and professional income; Third: income from investments and capital gains; Fourth: income from real estate; and Fifth: other income.

\section{Deduction}

Business income deduction. Costs for earning the incomes are typically deducted from taxable income. Such costs include staff costs, rents, depreciation of premises and equipment, fees paid to third parties for services, utilities, portion of travel expenses, and other expenses incurred during the normal run of business.

Nonbusiness expenses deduction. Gross employment income can deduct the following expenses for the purpose of calculating PIT taxable income: union contributions and pensions. Deductions are also allowed in relation to the individual and family status of the taxpayer. Tax credit is available for international double taxation. 
Personal allowances. None.

Rate. Individual taxable income falls into five brackets with corresponding rate of 10, 15, 20, 25, and 32 percent with different levels of credits by bracket.

Non-residents are subject to the earned income tax, withheld and remitted by the employer or other payer at a flat rate of 20 percent. Most investment income is subject to a withholding tax at 20 percent, with exception of income from debit bonds and interests from bank deposits at 10 percent.

Simplified regime for PIT. Similar to the CIT regime, a simplified regime is instituted for PIT. The regime is applied to the case when annual turnover does not exceed MZM 2.5 million. Under this regime, no cost deduction is allowed and the total turnover is taxed according to certain coefficients: 0.2 for sale of goods and merchandise sector; 0.2 for the accommodation and food and beverage sector, and 0.3 on revenue from all other sectors of activities.

\subsection{VAT (IVA)}

Mozambique began administering a VAT from January 1, 1998 and since then frequent changes have been made. The new VAT code (Law No. 32/2007 of December 301) was introduced and amended by Law No. 3/2012 of January 23. Three distinct VAT schemes co-exist: A normal scheme (standard rate of 17 percent), simplified scheme (5 percent on turnover tax), and exemption scheme.

Base: The VAT is consumption-based and follows destination principle. Credit invoice method for calculation of VAT liability is applied.

VAT threshold and exemption regime: The VAT code indicates the exemption threshold of MT750 thousands and allows for businesses under this threshold to voluntarily opt for normal VAT regime with the restrictions that if so choosing, they will be required to remain in the normal VAT regime for at least five years. This conforms to good practice in dealing with potential fraud schemes whereby those businesses may get in and out of the VAT net overnight for the sake of fraudulent refunds.

Problems lie with overly complex and long list of exempt goods and services and the co-existence of the simplified regime. The list of exempts is provided in chapter II, article 9 (supply of exempt goods and services), covering various sectors and commodities in agriculture, forestry, livestock, and fishery, health, education (provided either by public or private establishments), banking, real estate, state assignments, gambling, culture and art, military material, and others. NGOs and goods and services supplied by the public sector (e.g., museums, art galleries, parks, botanical gardens, and zoos), social entertainments, goods and services provided for cultural and artistic purposes are also exempt. The issue of exemption is even made more complicated when related to "mega projects," in which investors are eligible to VAT exempt certificates. As indicated in USAID (2012), different laws are de facto created to tailor different projects.

Rate. The standard rate is 17 percent. In addition, zero rate is applied to exports and multiple 
other items. Those businesses with revenues falling under the special VAT regime are subject to a rate of 5 percent (more detailed discussion follows).

Zero rating. The legal terms and provision for zero rating are nowhere to be found in the VAT Code. According to the information provided to the author by the AT, the goods and services listed in paragraph 10 of article 9 of the VAT Code are subject to zero rate (even though they are listed under the overall headlines of exemption. These items are multiple: "Supplies of maize, maize flour, rice, bread, iodide salt, powdered milk for babies of up to one year of age, wheat, wheat flour, fresh or chilled tomato, potatoes, onions, frozen horse mackerel, lighting petroleum, jet fuel, ordinary bicycles, condoms and insecticides.”

VAT Refunds. VAT refunds are covered in Articles 21-22 of the VAT Code. The law follows the normal practice in VAT refunds: the AT is supposed to review and decide on the legibility of the refund within 30 days and any delayed refunds amount will be subject to interest payment.

However the refund is not properly functional. Currently VAT collection is recorded on a gross basis and VAT refunds as an expenditure item. This inherently breaks the nature of a consumption based VAT and its integrity and mimics to a turnover tax. The IMF (July 2013) estimates that at the end of 2012, unsettled VAT refund requests have reached 1.3 percent of 2013 GDP.

Simplified regime for VAT. This regime exists in parallel with both the normal and exemption regimes (described above). It defines that Taxable persons are subject to the simplified taxation regime, if they (1) have an annual business volume above MT 750,000 and less than MT 2,500,000, (2) do not possess and are not required to possess regularly organized accounting for income-tax purposes, and (3) do not engage in operations of imports, exports, or related activities. These businesses are subject to a tax rate of 5 percent of the turnover (this amounts to a turnover tax). Similar to the exempt regime, if they choose this special regime, they must remain for at least five years.

\subsection{Fiscal Incentives}

Fiscal incentives have been instituted purportedly to serve multiple objectives. The new set of incentives is provided in the Law 4/2009 of 12 January, the Code of Fiscal Benefits, and went into effect from January 1, 2009. The mere existence of the fiscal benefits code in parallel to the incentives provided in separate tax codes (e.g., PIT, CIT, and VAT) shows the murkiness of the entire tax system and as such opens doors for direct negotiation with investors and discretion by tax administration.

Multiple types of fiscal incentives are available: tax holidays, tax rate deduction, investment tax credit, accelerated depreciation, exemption, and inflated expenses to deduct from taxable income. Incentives are offered by sector, geographical area, and type of investments. Compared to prior the 4/2009 Code of Fiscal Benefits, fiscal incentives tend to expand and be more generous.

As pointed out in Fjeldstad \& Heggstad (2011), the fiscal incentives setting favors capital 
intensive and foreign owed companies: such foreign-owned projects account for up to 12 percent of GDP but contribute less than 3 percent of tax revenues and 3 percent of employment. The AT provides estimates of fiscal expenditures for the income taxes (CIT and PIT) over the three years since the introduction of the new fiscal schemes (2009). Fiscal expenditures were very substantial, ranging from 16 to 23 percent of the total CIT and PIT collection and amounting to substantial leakage of almost 19 percent on average during this period. With the collection of income taxes of 6.8 percent of GDP, the leakage would be equivalent to approximately 1.3 percent of GDP in 2011.

\section{Measuring Productivity of Major Taxes and Policy Implications}

The review of Mozambique’s tax system highlights the following.

- The country has established a solid legal framework for a modern tax system.

- The overall tax intake is buoyant, suggesting the tax system has been successfully capturing the major tax handles evolving during the course of country's growth and development.

- While tax system is buoyant, it may not be feasible to expect a surge in revenues from new mega projects in extractive sector over the mid-term. This would imply that containing the deficits would depend more on rationalization of expenditures and that significant donor support remains critical.

- While the tax system is vibrant and set with sufficient instruments and legal framework, it is at best still in the process of transition.

- Tax burden on the corporate sector is relatively high compared with other SDAC countries.

- The complexity of tax regime, the mere existence of multiple schemes for small and medium taxpayers across tax codes, and the post 2009 overly generous system of fiscal incentives set in favor of certain types of investment, particularly capital-intensive, new mega projects - are among the few that collectively reflect the incoherence in the policy making and inherent conflicts among various objectives of tax policy reforms spanning over the past decade.

To set stage for policy recommendations for furthering the reforms of major taxes, we offer some estimates of productivity of CIT and VAT from regional perspectives. The analysis reconfirms the complexity and erosion of the base as a major channel for revenue leakage that more than compensating for the relatively high statutory rates in these taxes.

\section{Productivity of CIT and VAT from Regional Perspective}

\subsection{Productivity of CIT}

CIT productivity is calculated as the ratio between CIT collection as share in GDP and the standard statutory rate (Table 4). Of the 9 countries in the sample, Mozambique statutory rate is relatively high (only Zambia and Namibia has a higher rate while the rate in other countries 
is significantly lower). However, the CIT efficiency rate in Mozambique ranks at the low end (0.097). This implies erosion of the CIT base.

If Mozambique could strive to attain the level of efficiency of the best performer in this sample (Botswana), it would be able to collect an additional 3.74 percent of GDP (more than double the level of CIT intake as of now). Alternatively, at the average level of efficiency (0.143), Mozambique could have collected 4.57 percent of GDP or 1.47 percentage point of GDP higher than the current level of CIT effort. The range of additional CIT revenues as such would be 1.5 to 3.7 percent of GDP, depending on the comparator to be used.

Table 4. CIT efficiency rates in selected SADC countries

\begin{tabular}{|l|l|l|l|}
\hline Countries & Standard CIT statutory rate (\%) & CIT collection (\% of GDP) & CIT efficiency rate \\
\hline Botswana & 22 & 4.7 & 0.2136 \\
\hline Malawi & 30 & 2.8 & 0.0933 \\
\hline Mauritius & 15 & 2.7 & 0.1800 \\
\hline Mozambique & 32 & 3.1 & 0.0969 \\
\hline Namibia & 33 & 4.0 & 0.1212 \\
\hline South Africa & 28 & 5.6 & 0.2000 \\
\hline Swaziland & 30 & 2.7 & 0.0900 \\
\hline Zambia & 35 & 4.0 & 0.1143 \\
\hline Zimbabwe & 25.75 & 4.5 & 0.1748 \\
\hline & & Average & 0.1427 \\
\hline
\end{tabular}

Source: PWC (2013); IMF database; and authors’ estimates

\subsection{VAT}

Two measures of VAT efficiency are used to compare the relative functioning of the VAT in selected SADC countries (Table 5). Gross Compliance Ratio (GCR) is defined as the ratio between actual VAT collections to the potential VAT collection. VAT efficiency is defined as the ratio between actual VAT collection in terms of GDP and a VAT standard statutory rate.

It is clear that in terms of GCR, South Africa stands as the best performer (GCR of 0.805), while in terms of VAT efficiency ratio, Zimbabwe stands at the top (0.62). Either of these two measures indicate that Mozambique has much to catch up. At the GCR level of South Africa or VAT efficiency ratio of Zimbabwe, Mozambique should have been able to collect 10.79 and 10.54 percent of GDP, respectively, highlighting the significant gap in Vat collection in the order of about 5.5 percentage points of GDP. (Note 7) Compared with the average efficiency level of the countries in the sample, the VAT performance in Mozambique is much lower: 0.392 v. 0533 (CGR), and 0.306 v. 0.366 (VAT efficiency ratio). The same picture as 


\section{Macrothink}

Case Studies in Business and Management ISSN 2333-3324 2016, Vol. 3, No. 2

seen for the CIT regime, the standard VAT statutory rate in Mozambique of 17 percent is the third highest of the 12 countries in the sample-the fact that clearly implies significant erosion of the base.

Table 5. VAT efficiency in selected SADC countries

\begin{tabular}{|l|l|l|l|l|l|}
\hline Countries & $\begin{array}{l}\text { VAT Collection } \\
\text { (\% of GDP) }\end{array}$ & $\begin{array}{l}\text { Standard Statutory } \\
\text { VAT rate (\%) }\end{array}$ & $\begin{array}{l}\text { Estimated VAT } \\
\text { Potential (\% of GDP) }\end{array}$ & $\begin{array}{l}\text { Gross Compliance } \\
\text { Rate (GCR) }\end{array}$ & $\begin{array}{l}\text { VAT Efficiency } \\
\text { Ratio }\end{array}$ \\
\hline Botswana & 3.7 & 12 & 6.073 & 0.609 & 0.308 \\
\hline Madagascar & 2.2 & 20 & 15.600 & 0.141 & 0.110 \\
\hline Malawi & 5.6 & 16.5 & 12.291 & 0.456 & 0.339 \\
\hline Mauritius & 7.1 & 15 & 11.024 & 0.644 & 0.473 \\
\hline Mozambique & $\mathbf{5 . 2}$ & $\mathbf{1 7}$ & $\mathbf{1 3 . 2 7 9}$ & $\mathbf{0 . 3 9 2}$ & $\mathbf{0 . 3 0 6}$ \\
\hline Namibia & 6.1 & 15 & 9.198 & 0.663 & 0.407 \\
\hline South Africa & 6.9 & 14 & 8.572 & 0.805 & 0.493 \\
\hline Swaziland & 6.6 & 14 & 11.652 & 0.566 & 0.471 \\
\hline Tanzania & 4.5 & 18 & 11.901 & 0.378 & 0.250 \\
\hline Zambia & 3.9 & 16 & 7.271 & 0.536 & 0.244 \\
\hline Zimbabwe & 9.3 & 15 & 13.774 & 0.675 & 0.620 \\
\hline & & Average & & $\mathbf{0 . 5 3 3}$ & $\mathbf{0 . 3 6 6}$ \\
\hline
\end{tabular}

Source: WDI 2013, International Bureau of Fiscal Documentation, IBFD 2013, Government Finance Statistics (IMF), International Financial Statistics (IMF), World Economic Outlook (IMF), World Bank country reports, and authors' estimates

\subsection{Policy Implications for Further Tax Reforms}

\subsubsection{CIT}

In general, the CIT regime in Mozambique follows standards observed elsewhere in the world. The regime by and large is based on the worldwide income and the accounting of taxable income allows for deduction of expenses incurred in earning the income or maintaining the assets. The issue lies more in the detailed provisions of the CIT regime and in the 2009 Code of Fiscal Benefits. As presented, the fiscal incentive system tends to favor 
large, capital intensive projects and use various incentive instruments that de facto narrow the base and create opportunity for both evasion and avoidance. In order to compensate for the base erosion, the standard rate as currently set is high, relative to region and OECD countries. In addition, inefficiency, complexity, and loopholes derive from the multi-rate setting.

The analysis of the existing CIT regime in the country in the light of international experience in revenue policy reforms suggests that further reforms require the plugging of loopholes that lead to erosion of the base. Expanded and stabilized base would allow for rationalizing the rate structure. Opportunity to simplify the entire CIT regime would follow.

Broadening the base. Mozambique can feasibly broaden the base without reducing the incentives to invest as that allows for rate reduction and restructuring.

Fiscal incentives. The ever expansion of fiscal incentives since 2009 goes in opposite direction to the international trends. These provisions should be reviewed and simplified. Countries, especially the OECD, tend to limit their fiscal incentives to only some major forms, in particular, investment tax credit, or accelerated depreciation. Empirical studies and theories show that these instruments are more effective in attracting marginal investments, restraining the fiscal losses, and preserving neutrality. (Note 8) Tax holidays and CIT rate reduction are considered as the two bluntest instruments that tend to generate 'flight by night' effect on firms' investment decision. At national level, OECD countries no longer offer tax holidays. It is also worth noting that the impact of fiscal incentives for FDI as offered by host country is dependent upon home country tax policy and the availability of a tax treaty between home and host countries. If the home country allows for foreign tax credits, and if there is no "tax sparing” treaty, generous tax relief in Mozambique simply means a pure transfer of fiscal revenues to the FDI home country without any benefits gained by the foreign investors. (Note 9)

Thin capitalization rule. It has become common practice that to avoid erosion of the base and risky investments, tax administrations set a limit on the debt-equity ratio in determining taxable income of a business entity. While the ratio is set differently in different countries, it has to be specific and enshrined in the law-this element of the good practice is missing in the current Mozambique CIT law.

Simplification of fiscal depreciation schedule. The existing depreciation scheme is complicated with about 20 categories. According to international good practice, tangible and intangible assets are to be lumped into about or fewer than 5 categories. Such simplification tends to curb abuse and reduce both compliance as well as administration costs.

Treatment of capital gains. The current CIT code does not allow for indexation of purchase price in determining the taxable amount from capital gains. This practice overstates the gains and may become disincentive to long-term investments.

Rate. The rate structure should be simplified with only one rate, which is to be reduced over time in accordance to international trends in parallel with measures aimed at expanding the base. Due to ever more intense tax competition, countries tend to reduce their CIT rate. During the period of 1990-2000, the median CIT rate in OECD countries is 27 percent, while 
the minimum rate is 8.5 percent (Switzerland) and maximum 35.2 percent (Belgium).

Special regime for CIT. The existence of such regime is redundant and should be abolished as there is already ISPC to deal with small and medium sized businesses.

\subsubsection{PIT}

The legal basis for PIT collection is good. The tax, by design, is broad-based and applied virtually without discernable distinction between citizens and foreigners. Enhancing the PIT efficiency and equity however would require holistic review and further consideration.

The PIT coverage. On the one hand, a PIT serves as an instrument of income redistribution (in addition to revenue raising). On the other hand, caution or balance is to be made to ensure that the regime does not create undue burden and barrier to formalization (especially wage income earners end up being 'trapped' in the system while others could have opportunity to stay out of formality and pay no taxes). This relates to the boarder issue of how to set up the threshold when a taxpayer has to start paying their PIT: whether the tax is to be focused only on high/medium income earners while tax administration is to be improved to ensure high compliance. This is a delicate choice that policy makers must make, provided that simply following PIT coverage in in developed countries may not always useful in the context of Mozambique.

PIT tax credit. The existing PIT regime does not allow for tax relief specifically given to the poor or those in low income brackets. It is given instead on the basis of the five different income brackets: those in higher income brackets enjoy higher level of credit. This is completely against the equity principle underlying a functional PIT. It is also suggested that threshold and credit be adjusted annually for inflation to avoid bracket creep.

Number of brackets. Five is too many, even though the number of brackets in Mozambique's PIT is not a real outlier compared with some other SADC countries (Table 6). It may be conceivable that more brackets would tend to allow for more distinction and better separation of taxpayers with different levels of income and thereby allow for vertical equity. However, it should be noted that the higher the number of brackets, the more complicated administration and thereby the more likely tax evasion/avoidance. International experience also shows that a complex multi-bracket PIT does little to promote equity. (Note 10) It is suggested that the Government consider reducing the number of tax brackets to three or four.

Table 6. PIT regimes in selected SADC countries

\begin{tabular}{|l|l|l|l|}
\hline Countries & $\begin{array}{l}\text { PIT Thresholds } \\
\text { (US Dollars) }\end{array}$ & $\begin{array}{l}\text { PIT Threshold } \\
\text { (\% of GDP per capita) }\end{array}$ & PIT Rates (\%) \\
\hline Angola & 261 & 0.04 & $5 ; 6 ; 7 ; 8 ; 9 ; 10 ; 11 ; 12 ; 13 ; 14 ; 15 ; 16 ; 17$ \\
\hline Botswana & 4230 & 0.45 & $5 ; 12.5 ; 18.75 ; 25$ \\
\hline DRC & 573 & 2.42 & $15 ; 20 ; 22.5 ; 25 ; 30 ; 32.5 ; 35 ; 37.5 ; 40$ \\
\hline Lesotho & 0 & 0 & $22 ; 35$ \\
\hline Madagascar & 114 & 0.25 & 20 \\
\hline
\end{tabular}




\begin{tabular}{|l|l|l|l|}
\hline Malawi & 578 & 2.16 & $15 ; 30$ \\
\hline Mauritius & 8710 & 0.98 & 15 \\
\hline Mozambique & 56 (Note 11$)$ & N/A & $10 ; 15 ; 20 ; 25 ; 32$ \\
\hline Namibia & 4811 & 0.83 & $18 ; 25 ; 28 ; 30 ; 32 ; 37$ \\
\hline Seychelles & 0 & 0 & $10 ; 15$ \\
\hline South Africa & 6255 & 0.83 & $18 ; 25 ; 30 ; 35 ; 38 ; 40$ \\
\hline Swaziland & 0 & 0 & $20 ; 25 ; 30 ; 33$ \\
\hline Tanzania & 1246 & 2.05 & $13 ; 20 ; 25 ; 30$ \\
\hline Zambia & 4620 & 3.13 & $25 ; 30 ; 35$ \\
\hline Zimbabwe & 3000 & 3.97 & $20 ; 25 ; 30 ; 35 ; 40 ; 45$ \\
\hline
\end{tabular}

Source: IBFD, IMF

Rate. Currently there exists significant disparity between the CIT standard rate (32 percent) and the highest marginal PIT rate (30 percent). This would create opportunity for tax avoidance, particularly for individual income taxpayers into the second category (business and professional income earners). These rates should be harmonized (i.e., set at the same level).

Simplified regime for PIT. Again, this is redundant and suggested to be removed in order to avoid any conflicts and duplication with the ISPC.

\subsubsection{VAT}

Exempt and zero rated items. The VAT code provides an expansive list of exempt and zero-rated items. Our analysis of the VAT efficiency (Table 5) indicates that if base erosion can be contained, relatively the country could be able to raise the VAT collection by 5.5 percentage points of GDP. The list of exempt and zero rated items must be reviewed and rationalize. The revision of the VAT code is required to specify - in transparent terms - the distinct provisions for exempts and zero rating (the current state of the Law is inherent with confusing terms that mix exempt and zero rating schedules).

It is worth emphasizing some points on exempt and non-export zero rating (see Annex 5) for an illustration of the case of producing/consuming bread-considered typically as a basic good).

- Exemptions tend to erode the base, deplete the potential revenue intake, have unclear impact on the poor, and potentially break the chain and thereby induce cascading problems. Even worse, exemption is likely to ratchet up and as seen from Mozambique's VAT code-exemption of food/agriculture or fishery products seemingly lead to exemptions of inputs for these sectors.

- To effectively relieve tax burden on the poor through exemption, it is required that for a credit-invoiced based VAT, the exemption be allowed exactly at the final stage, where the poor consume the good. Otherwise, the tax burden is even higher than that in a non-exempt situation due to cascading effect. 
- For zero rating, under invoice-based credit method, the tax revenues are to be eliminated only if the last stage is zero-rated (hence the poor can benefit from intended zero rating provision). Zero rating of any stage prior to the final one does not affect the total tax burden borne by the whole chain.

On the efficiency and practicality grounds, it is suggested that Mozambique consider to eliminate as much as possible the long list of non-export zero rated items, specifically maize flour, rice, bread, iodide salt, baby powdered milk, wheat flour, tomatoes, potatoes, onions, frozen horse mackerel, lighting petroleum, jet fuel, bicycles, condoms and insecticides. To support the poor, public expenditures or social programs prove to be more cost-effective than VAT relief provisions. Similarly, rationalization of the long list of exemption requires some review and distinction of 'regular/for profit' supplies of goods and services (health services and medication, agricultural items supplied by large business entities, and for profit education, as well as commercial services provided by private, NGO, and public entities). For agriculture, fishery sector, if the farms have turnover above the set threshold, they should be subject to the VAT regime and if below, they should be treated under the ISPC. Currently, some definition leaves the AT with substantial discretion to interpret what items are to be exempt and what not (for example, article 10 partly restricts the goods and services by NGOS to exempt regime only if they do not compete directly with VAT taxable persons. The question is how that condition is to be determined by tax administration authority).

Building institution and capacity for tax expenditure and tax gap analysis. The analysis of tax expenditures and tax gaps is essential for policy review and reforms. Dedicated unit within the AT should be created with sufficient training and capacity in collecting, mining, and analyzing data. Revenue forecasting modeling and techniques are required to conduct such important exercises. Annex 6 presents the overview of tax expenditure and gap analysis with the VAT as the proposed pilot.

Setting the VAT threshold. The efficiency of the exempt regime is dependent upon setting the VAT threshold right. There exists no unique recommendation on any specific threshold to be applied to a country, but cross country comparison may offer some reference for Mozambique. Among the SADC countries with a VAT, thresholds are set at vastly different levels with a median of USD 32,097. (Note 12) The current threshold for the VAT exempt scheme in Mozambique is MT 75 thousands, equivalent to around USD23,148, while the upper threshold for the special regime is MT2.5 million or more than USD77 thousands. (Note 13) Once the special regime is abolished, it is recommended that the exempt threshold be revisited and revised as necessary (probably somewhere in between the current thresholds for the special regime, USD 23,148 and USD 77 thousands).

VAT refunds. Properly managed and timely VAT refund is essential to ensure the tax is an efficient and pure tax on consumption. Any delay in VAT refunds would add a layer of "hidden costs" to registered firms and thus discourage investment. Box 1 summarizes lessons learned from advanced tax administrations in dealing with VAT refunds. 
Box 1. Administration of VAT refunds: Worldwide experience

Most developed countries, including New Zealand, Japan, Canada, and EU countries, allow for complete refund of all excess tax credit, while developing countries often embark upon a hybrid system of refunds and carry-forward arrangement of the excess credit). One proven approach to administration of VAT refunds is to establish a "gold-silver" scheme, in which refund claimants are grouped into "gold," "silver," and "others" categories. The criteria for the grouping must be simple and transparent. They are generally related to the claimant's history of exports, book keeping, tax compliance, and audit of records by tax officials. Those classified in "gold" or "silver" categories are granted with such privileges as fast, and without pre-approval audit refunds. The scheme helps tax administrations focus on checking and auditing high-risk refund claimants.

Special regime for VAT. Similarly to the case for CIT and PIT, this special regime should be removed. For VAT, the co-existence of this regime with the other two (the normal and exempt schemes) creates loopholes for evasion and unnecessary uncertainty to the business community and increases both administration and compliance costs. A modern tax system should have a unique, dedicated regime to deal with micro/small taxpayers, but does not retain duplicated special regimes in all major types of taxes (CIT, PIT, and VAT).

\section{References}

AFRODAD (African Forum and Network on Debt and Development). (2011). What has tax got to do with development? A critical look at Mozambique’s tax system.

Doing Business-Measuring Business Regulations. (2013).

Fjeldstad, O., \& K. K. Heggstad. (2011). The Tax Systems in Mozambique, Tanzania and Zambia: Capacity and Constraints (mimeo).

Government of Mozambique. (2003). Corporate Income Tax Code (IRPC) as amended by Decree 61/03.

Government of Mozambique. (2003). Personal Income Tax Code (IRPS) as amended by Decree 61/03.

Government of Mozambique. (2009). Law 4/2009 of 12 January. Code of Fiscal Benefits.

Government of Mozambique. (2012). Regulations of the Value Added Tax (VAT) Code. DECREE $N^{\circ}$ 7/2008, OF APRIL 16, 2008 as amended by Decree $N^{\circ}$ 4/2012 OF FEBRUARY 24, 2012 (Updated in August 2012).

Government of Mozambique. (2012). Value Added Tax Code. LAW No. 32/2007 OF DECEMBER 31, AMENDED BY LAW No. 3/2012 OF JANUARY 23 (Updated in August 2012). 
Harberger, A. C. (1980). Tax Neutrality in Investment Incentives. In H. Aaron \& M. Boskin, (eds.), The Economics of Taxation (Studies of Government Finance: Second Series). Washington D.C.: Brookings Institution.

IMF. (2013). Republic of Mozambique, IMF Country Report No. 13/200.

Musgrave, A. R., \& Peggy, B. M. (1989). Public Finance in Theory and Practice (5th edition). New York: Mcgraw-Hill College.

PWC. (2013). Worldwide Tax Summaries: Corporate Taxes.

Schneider, F., Buehn, A., \& Montenegro, C. E. (2010). Shadow Economies All over the World-New Estimates for 162 Countries from 1999 to 2007. Policy Research Working Paper, 1(9), 1-66.

USAID. (2012). Taxation in the Agricultural Sector in Mozambique. Draft paper prepared by DAI and Nathan Associates. Mimeo.

World Bank. (2013). International Development Association Program Document for Ninth Poverty Reduction Support Credit.

World Development Indicators.

\section{Notes}

Note 1. Source: World Development Indicators (WDI); and Schneider et al., 2010.

Note 2. The following terms and acronyms will be used interchangeably in the remaining sections of the report: Imposto sobre o Rendimento das Pessoas Colectivas (IRPC, or corporate income tax, CIT), Imposto sobre o Rendimento das Pessoas Singulares (IRPS or personal income tax, PIT), Imposto sobre o Valor Acrescentado (IVA or value added tax, VAT).

Note 3. Source: Mozambique’s Ministry of Finance.

Note 4. The data is based on WDI which defines total tax rate as share of commercial profits as follows. The indicator measures the amount of taxes and mandatory contributions payable by businesses after accounting for allowable deductions and exemptions as a share of commercial profits. Taxes withheld (such as personal income tax) or collected and remitted to tax authorities (such as value added taxes, sales taxes or goods and service taxes) are excluded.

Note 5. Cross country comparison of key elements of the CIT regimes in SADC (including rate, deductible items, depreciation schedules, loss carried forward/backward, thin capitalization rules) draws on the PWC Corporate Income Tax Summaries and is on file with author.

Note 6. Particularly, article 61, paragraph 1, indicates that: "When a liable person's indebtedness to an entity not residing in Mozambique with whom there is a special 


\section{Macrothink}

Case Studies in Business and Management

ISSN 2333-3324

2016, Vol. 3, No. 2

relationship, as defined in this article, is excessive, the interest on the part considered to be excessive is not deductible for the purposes of determining taxable profit." This article does not refer to any restriction in terms of allowable debt-equity ratio.

Note 7. The gap is estimated as the difference between the collection at South Africa's GCR (10.79\% of GDP) or Zimbabwe's VAT efficiency ratio (10.54\% of GDP) and the current actual collection in Mozambique (5.2\% of GDP), provided that the standard rate is the same, $17 \%$.

Note 8. Tax neutrality requires that tax incentives not distort the before-tax ranking of different investments. To support the positive role of tax incentives in economic growth, various theoretical tax neutrality schemes such as Musgrave, Samuelson, \& Harberger neutralities are designed. For concise discussion on these neutrality schemes, see Harberger (1980, pp. 303-309).

Note 9. "Tax sparing" refers to a treaty between home and host countries, by which firms were allowed to take foreign tax credit in their home country as if the tax were paid in the host country even when the firms were granted tax holidays by the host country.

Note 10. This is the underlying argument for flat income tax advocates in OECD countries.

Note 11. Approximated value of the threshold provided for a single or legally separated taxpayer at the exchange rate of MT32.4/USD1 as of February 27, 2014.

Note 12. Source: IMF Database with author's update for the case of Mozambique (in file with author).

Note 13. At exchange rate of MT32.4/USD1 as of February 27, 2014.

\section{Copyright Disclaimer}

Copyright for this article is retained by the author(s), with first publication rights granted to the journal.

This is an open-access article distributed under the terms and conditions of the Creative Commons Attribution license (http://creativecommons.org/licenses/by/3.0/). 